\title{
Outcome of operative management of displaced acetabular fracture: A retrospective analysis / of a tertiary care center of a developing country
}

\author{
Suresh Uprety, Prabesh Singh Bhandari \\ Department of orthopaedics and trauma surgery, Maharajgunj Medical Campus, Institute of Medicine \\ Corresponding author: Suresh Uprety \\ Email : drsuprety@gmail.com
}

\begin{abstract}
Introduction: Displaced acetabular fracture is a consequence of high energy trauma and commonly seen in young population. There has been increasing trend towards operative management of these injuries to provide early mobilisation and prevent complication of incongruent reduction.

Methods: A retrospective analysis on clinical outcome of operative management of 16 displaced acetabular fracture using Merle d'Aubigne hip score carried out at university teaching hospital carried out between 2015 to 2017 AD

Result: TheMerle d'Aubigné hip score at final follow of 3 to 30 months period ranged from 7 to 17. The average score was 13.8 . Very good result was seen in $68.75 \%$, fair result in $12.5 \%$.

Conclusion: Operative management of displaced acetabular fracture gives excellent to good short term outcome in most of the cases.
\end{abstract}

Keywords: Displaced acetabulum fracture; Judet and Letournel classification; Merled'Aubigné hip score.

\section{Introduction}

Acetabular fractures are high energy fracture with high mortality and associated injuries. With the rising trend in road traffic associated fatalities in our country incidence of acetabular fractures is expected to rise proportionately. ${ }^{1}$ Development in imaging technology with computed tomography and better understanding of anatomy and biomechanics of acetabulum clear indications for operative treatment of acetabular fracture has been well laid out.

Over past few decades management of displaced acetabular fracture has changed from nonoperative to operative. Subsequently, open anatomical reduction of the articular surface combined with rigid internal fixation and early mobilisation became the standard treatment for these injuries. $^{5}$

Surgical treatment of acetabular fractures requires a prolonged and very steep learning curve. The experience of the surgeon and the approach to the treatment of the fracture also affect the clinical outcome. Both the human and logistics are in short supply in our part of the world having to cope up with increasing number on such severe injury.

This study was carried out to shed light on epidemiological aspect and experience of a tertiary level health care centre of a third world country in treating displaced acetabular fracture.

\section{Methods}

This is a retrospective observational study carried out at university teaching hospital, Nepal. The study period was between 2015 AD to 2017AD. The patients with displaced acetabular fracture who were managed operatively were identified from the hospital records and included in the study. The fracture pattern were classified based on Judet and Letournel classification system using Anterior Posterior Pelvic inlet outlet views ${ }^{2}$. Plain radiographic findings were confirmed with CT scan (Figure 1) 


\section{Surgical Approach and fracture fixation details:}

Kocher-Langenbeck approach on lateral decubitus position was used for posterior wall and posterior column and Ilioinguinal approach was used for anterior wall or anterior column fracture of acetabulum. For bicolumnar fracture, (either simultaneous or staged surgery with interval of 2 to 5 days was performed). Depending upon fracture configuration, single or double $3.5 \mathrm{~mm}$ reconstruction plates were used for fracture fixation. A lag screw or spring plate were used for small osteochondral fragments .Intraoperatively fluoroscopy was used to confirm the acceptability of the reduction as well as to see hardware breech into the hip joint.

Postoperatively Quality of fracture reduction was assessed with $\mathrm{X}$ rays, which included anterio-posterior views and two $45^{\circ}$ oblique Judet views and CT scans wherever feasible in subsequent follow up. All the patients were clinically evaluated using Merle d'Aubigné Hip Score for functional assessment till the final assessment taken during the study period. ${ }^{3}$ (Table 1) ( Figure 1)

Complications during the procedure and encountered there after till the final follow up (3-30 months) was recorded .

Table 1: The Merle d'Aubigné Hip Score 7

\begin{tabular}{|c|c|c|}
\hline Criteria* & Assessment & $\begin{array}{l}\text { Score } \\
\text { (Points) }\end{array}$ \\
\hline \multirow[t]{7}{*}{ Pain } & Intense and permanent & 0 \\
\hline & Severe even at night & 1 \\
\hline & $\begin{array}{l}\text { Severe when walking, prevents } \\
\text { any activity }\end{array}$ & 2 \\
\hline & Tolerable with limited activity & 3 \\
\hline & $\begin{array}{l}\text { Mild when walking, disappearing } \\
\text { at rest }\end{array}$ & 4 \\
\hline & $\begin{array}{l}\text { Mild and inconsistent; normal } \\
\text { activity }\end{array}$ & 5 \\
\hline & No pain & 6 \\
\hline \multirow[t]{4}{*}{ Mobility } & $\begin{array}{l}\text { Ankylosis with bad position of } \\
\text { hip }\end{array}$ & 0 \\
\hline & $\begin{array}{l}\text { No movement, pain or slight } \\
\text { deformity }\end{array}$ & 1 \\
\hline & Flexion $<40^{\circ}$ & 2 \\
\hline & Flexion $40^{\circ}-59^{\circ}$ & 3 \\
\hline
\end{tabular}

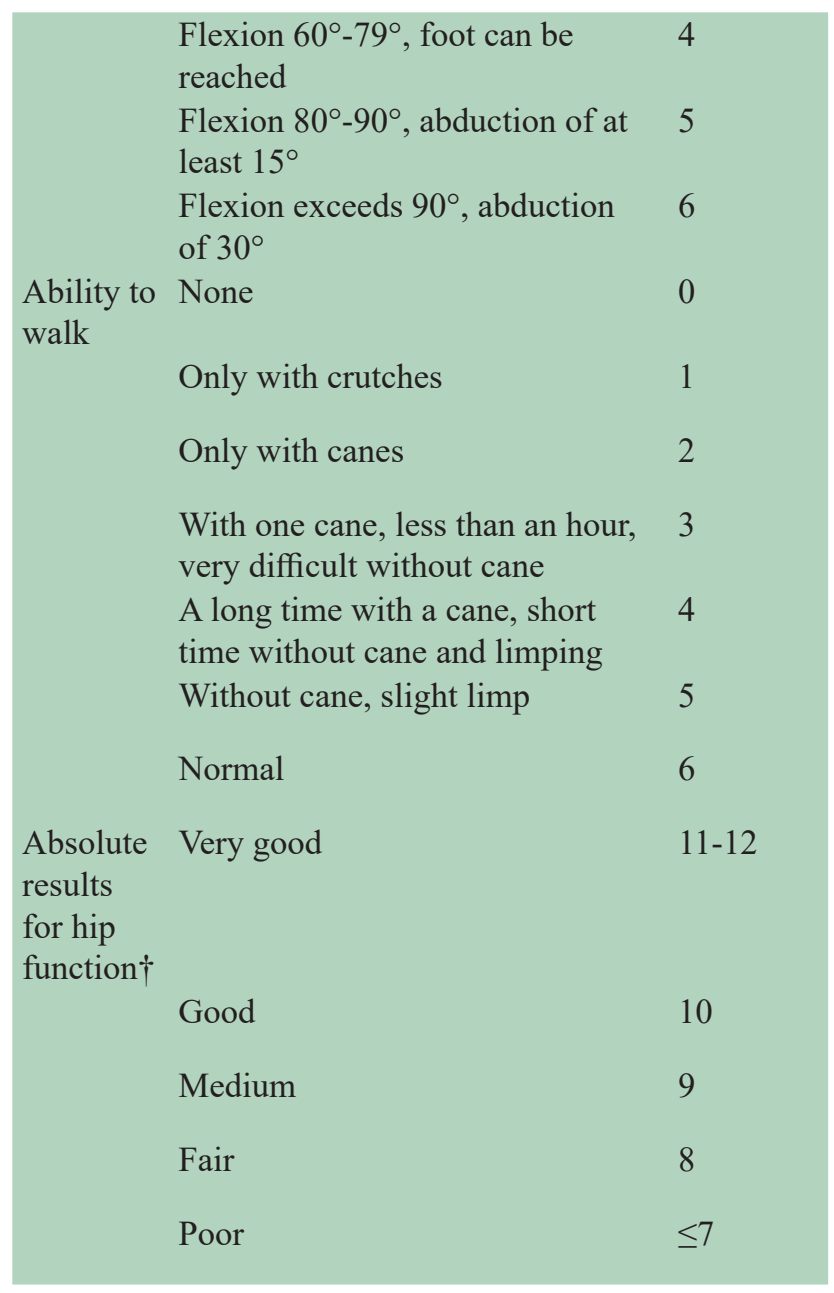

*The Merle d'Aubigné hip score7 includes the parameters pain, mobility, and ability to walk, with each rated from points (worst condition) to 6 points (best condition). $\uparrow$ Addition of the scores for pain and mobility results in an

absolute estimation of hip function. †Difference between preoperative and postoperative status (all three

categories, with pain and walking ability multiplied by two before being added).

\section{Result}

Total no 16 patients were reviewed in the study with follow-up of three months to 30 months with average of 13.68 month. There were 8 male and 8 female patients. The age of the patients ranged from 19 to 65 years with the average age of 33.8 years. There were 6 elementary and 10 associated fractures according to the Leturonal and Judet classification. (Table 2) 
The most common cause of injury was road trafficaccident followed by fall from heightwhich was $12(75 \%)$ and $4(25 \%)$ respectively. Out of 16 patients there were 5 anterior wall, 6 posterior column and 5 both column fracture. Age of the patients ranging from 19 years to 65 years. There were 8 males and 8 females. (Table 3 )

\section{Table 2 :Fracture pattern: Leturonal and Judet}

$\begin{array}{lcll}\text { Elementary fractures: } & & \text { Associated fracture } \\ \text { Anterior wall : } & 2 & \text { Both column : } 5 \\ \text { Posterior column : } & 2 & \text { Transverse } & : 4 \\ \text { Posterior wall : } & 2 & \text { Posterior } & : 1\end{array}$

Table 3: The Merle d'Aubigne score at final follow up
Final outcome evaluation score was carried out using the Merle d'Aubigné Hip score. The final follow-up ranged from 3 to 30 months period. Merle d'Aubigné hip score at final follow up ranged from 7 to 17 . The average score was 13.8. (Table 4)

Table 4: Absolute result of hip function (according to The Merle d'Aubigné Hip Score)

$\begin{array}{lll}\begin{array}{l}\text { Absolute result for hip } \\ \text { function }\end{array} & \text { Percentage } & \text { Result } \\ \text { Very good } & (10-12) & 11(68.75 \%) \\ \text { Good } & (10) & 0 \\ \text { Medium } & (9) & 1(6.25 \%) \\ \text { Fair } & (8) & 2(12.5 \%) \\ \text { Poor } & (<=7) & 2(12.5 \%)\end{array}$

\begin{tabular}{|c|c|c|c|c|c|}
\hline SN & Age(yrs) & Sex & Type of fracture & Follow up (Months) & $\begin{array}{l}\text { Merle d'Aubigne Hip } \\
\text { score }\end{array}$ \\
\hline 1 & 35 & $\mathrm{~F}$ & Anterior column & 12 & 13 \\
\hline 2 & 26 & $\mathrm{~F}$ & post column & 14 & 17 \\
\hline 3 & 39 & $\mathrm{~F}$ & ant column & 12 & 16 \\
\hline 4 & 40 & M & Both column & 3 & 13 \\
\hline 5 & 20 & $\mathrm{~F}$ & Both column & 30 & 16 \\
\hline 6 & 52 & M & Posterior column & 12 & 14 \\
\hline 7 & 43 & M & Posterior wall & 24 & 17 \\
\hline 8 & 26 & M & Anterior wall & 15 & 7 \\
\hline 9 & 56 & $\mathrm{M}$ & Posterior wall & 15 & 7 \\
\hline 10 & 24 & $\mathrm{~F}$ & Both column & 9 & 13 \\
\hline 11 & 65 & $\mathrm{~F}$ & Anterior wall & 12 & 16 \\
\hline 12 & 19 & $\mathrm{~F}$ & Both column & 12 & 15 \\
\hline 13 & 20 & $\mathrm{~F}$ & Transverse post wall & 9 & 9 \\
\hline 14 & 24 & $\mathrm{M}$ & Both column & 10 & 8 \\
\hline 15 & 22 & $\mathrm{M}$ & Anterior column & 12 & 8 \\
\hline 16 & 30 & M & Posterior column & 18 & 15 \\
\hline
\end{tabular}


Few common complications were also encountered patients undergoing surgery. Deep Infection was seen in one case. The infection was managed with debridement but there was no osteoarticular involvement but patient had mild persistent pain but no discharging wounds. One case of avascular necrosis of femoral head occurred. There was radiolocation of hip which occurred due to patient not and femoral head fracture was identified. Iatrogenic sciatic nerve palsy was seen in 2 cases which recovered over follow-up. (Figure 2)

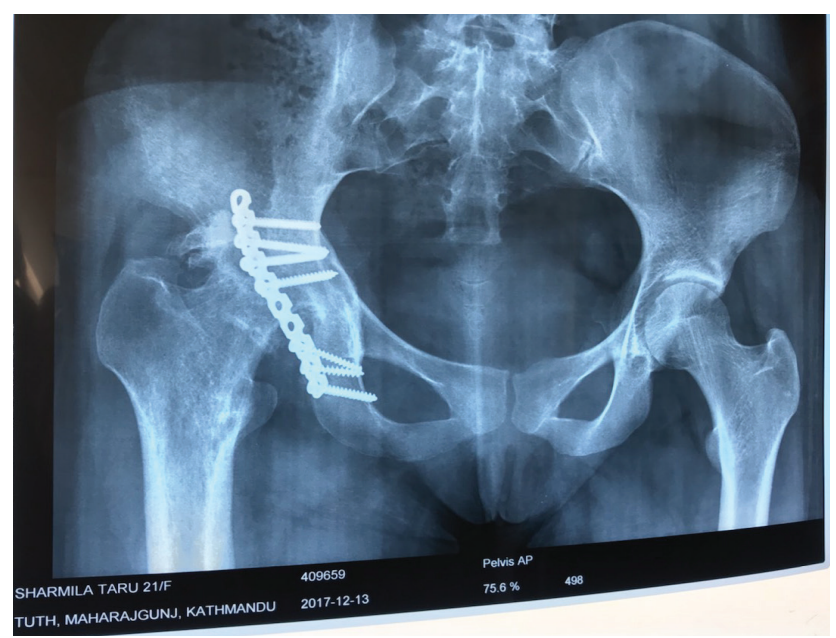

Figure 2 : Avascular necrosis with osteoarthritis on the right side
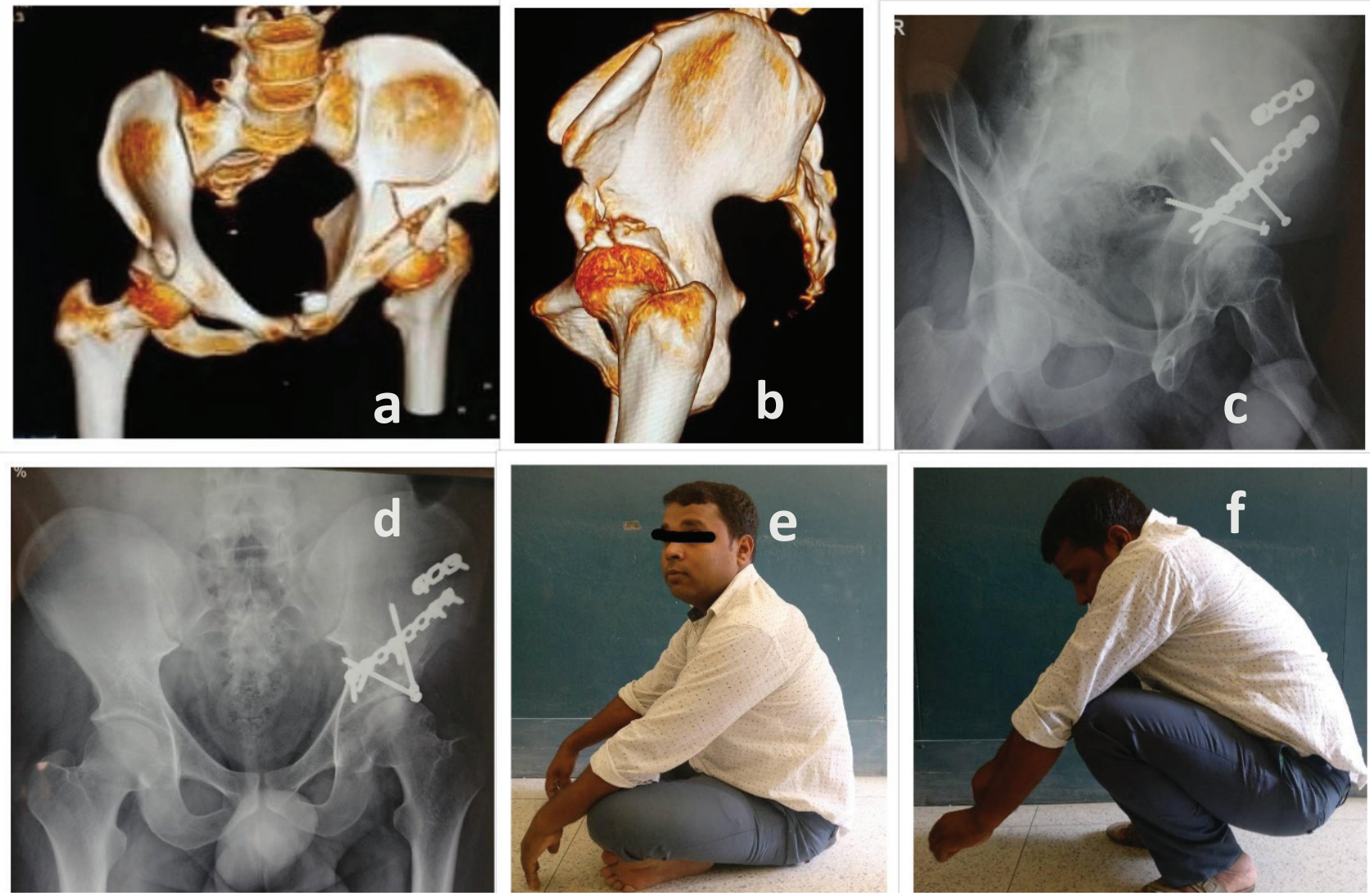

Figure: 1.a,b 3-D CT reconstruction view of anterior column and posterior wall injury. c,dXray at final follow-up. e,f clinical photos at final follow up 18 months. 


\section{Discussion}

The Enigma around the operative management of acetabular fracture was broken by works of letuonal and judet . ${ }^{4}$ Now the anatomical basis for stability of acetabulum fracture and the indications for operative management has been well laid out.

It has now been established that the functional outcome of the acetabular fracture managed by open reduction to achieve congruent joint is better than non-operative treatment. (judet + Recent IJO)

In our country incidence of such is in increasing trend with human resource as well as centres catering such injuries is scarce. Paucity of literature on operative management of acetabular fracture further strengthens on the fact that there are only handful of centres managing these injuries with open reduction and internal fixation. There have been two of such literature reported from Nepal, each mentioning 40 and 33 cases each both showing excellent outcome of operatively managed acetabular fracture. ${ }^{6,7}$

Acetabular injury is prevalent among the young individuals. The age of the patients in our study ranged from 19 to 65 yrs with the average age of 33.8 years. The average age was 38.4 years (range 19-68 years). ${ }^{8}$ The average age 39 years (range: 21 to 65 years) were operated for acetabular fracture. ${ }^{7}$ Similarly patients suffering from pelviacetabualr injury had mean age of 31.4 years.$^{6}$ These findings suggests that acetabular fractures are common in young middle aged patients in our part of the world

Our study has revealed that road traffic accident is the most common mode of acetabular injury $75 \%$ which was followed by $25 \%$ fall from height .similar findings were noted in the other study . Twenty one patients $(63 \%)$ had acetabular injury related with motor vehicle accidents and nine $(24 \%)$ of them had motorbike accidents ${ }^{6,7}$

Both column fracture is the most common pattern of injury seen in our series with $31.25 \%$.

Out of 40 patients with acetabular fracture, the commonest fracture was both column in 12 patients which accounted for $30 \%$ of total injury. ${ }^{6}$ Out of 33 patient bicolumnar fracture was seen in 15 patients which is $45.5 \%$ of total injury. $^{7}$

All these studies shows that bicolumanar fracture being the commonest in all the series.

The reason for this might be related to the mode of injuries which is common in all these studies which is road traffic accidents which is a high velocity injury.

In a carefully selected group of patients good or excellent results can be achieved. According to The Merle d'Aubigné Hip Score, good or excellent result is regarded as those where outcome is more than $70 \%$. (Table 5)

Table 5: Comparisons of outcome with published results (according to The Merle d'Aubigné Hip Score)

\begin{tabular}{|c|c|c|c|}
\hline & & cases & $\begin{array}{l}\text { Result (good/ } \\
\text { excellent) }\end{array}$ \\
\hline Mayo et al ${ }^{10}$ & (1994) & 163 & $75 \%$ \\
\hline Mata et al $^{9}$ & (1996) & 255 & $76 \%$ \\
\hline Gupta RK et al ${ }^{8}$ & (2007) & 63 & $74 \%$ \\
\hline Shrestha D et al ${ }^{7}$ & (2014) & 33 & $78 \%$ \\
\hline Current Study & & 16 & $68.75 \%$ \\
\hline
\end{tabular}

Iatrogenic nerve injury especially sciatic nerve during Kocher-Langenbeck approach is a well-known complication.(incidence of iatrogenic sciatic $\mathrm{N}$ Injury). Two cases $(12.5 \%)$ of iatrogenic sciatic nerve injury was encountered in our study which ultimately recovered during follow-up. In study of Gupta RK et al 3.17\%(2/63) one had partial recovery and the other did not recover. Shrestha D et al had 6\% (2/33) with complete recovery during follow-up. ${ }^{6,7}$

Careful positioning of retractors during surgery and avoiding tension to nerve by keeping hip and knee in suitable position to avoid stretching of nerve can minimize risk of nerve injury.

In our study $6.25 \%(1 / 16)$ of avascular necrosis occurred. In the study of operative treatment of acetabular fractures from the third World, 3.17\% (2 of 63), had avascular necrosis which was quiet low probably because, during the posterior approach, fractured acetabular fragment was approached from the iliac/ischial side. ${ }^{8}$ The capsule was only opened if reduction was not achievable without opening the capsule or, pre-operatively, there was evidence of an intra-articular loose bony fragment. ${ }^{8}$ In our study too we had to access the joint by opening the joint capsule.

Our study couldn't compare between the radiological outcomes with the functional outcome due to unavailability of the records of individual patients in our setting .So 
that the correlation between the clinical and radiological outcome couldn't be established. The number of cases enrolled in the study as well as duration of follow-up was less compared to other study. Though we achieved good functional result longer follow up and larger study population would have further strengthened our findings.

\section{Conclusion}

Road traffic accident is the major cause of acetabular fracture. It is affecting young and productive age group. Opearatively managed displaced acetabular fracture gives good to excellent early outcome. A study with large number of patients with radiological and clinical evaluation and longer follow up will probably elaborate the present finding.

\section{Conflict of interest}

Authors have no conflict of interest to declare.

\section{References}

1. World Health Organization. Global tuberculosis control: epidemiology, strategy, financing: WHO report 2009. World Health Organization; 2009.

2. Judet R, Judet J, Letournel E. Fractures of the acetabulum: Classification and surgical approaches for open reductionpreliminary report. JBJS. 1964 Dec 1;46(8):1615-75 https://doi.org/10.2106/00004623-196446080-00001

3. d'Aubigne RM, Postel M. Functional results of hip arthroplasty with acrylic prosthesis. JBJS. 1954 Jun 1;36(3):451-75; https://doi.org/10.2106/00004623195436030-00001.

4. Judet R, Judet J, Letournel E. Fractures of the acetabulum: Classification and surgical approaches for open reductionpreliminary report. JBJS. 1964 Dec 1;46(8):1615-75 https://doi.org/10.2106/00004623-196446080-00001.

5. Tornetta P. Displaced acetabular fractures: indications for operative and nonoperative management. JAAOS-Journal of the American Academy of Orthopaedic Surgeons. 2001 Jan 1;9(1):18-28. https://doi.org/10.5435/00124635-200101000-00003

6. Kumar Sharma U, Basnyat A, Rijal K, Kaji Shrestha B, Banskota B, Kumar Banskota A. CT evaluation of pelvic and hip fractures. Journal of the Nepal Medical Association. 2013 Oct 1;52(192). https://doi.org/10.31729/jnma.2431
7. Shrestha D, Dhoju D, Shrestha R, Sharma V. Acetabular fracture: Retrospective analysis of thirty three consecutive cases with operative management. Kathmandu Univ Med J (KUMJ). 2014 Oct;12(48):279-87.

8. Gupta RK, Singh H, Dev B, Kansay R, Gupta P, Garg S. Results of operative treatment of acetabular fractures from the Third World-how local factors affect the outcome. International orthopaedics. 2009 Apr 1;33(2):347-52; https://doi.org/10.1007/s00264007-0461-3; PMid:17940767 PMCid:PMC2899060.

9. Matta JM. Fractures of the acetabulum: accuracy of reduction and clinical results in patients managed operatively within three weeks after the injury. JBJS. 1996 Nov 1;78(11):1632-45. https://doi.org/10.2106/00004623-199611000-00002

10. Mayo KA. Open reduction and internal fixation of fractures of the acetabulum. Results in 163 fractures. Clinical orthopaedics and related research. 1994 Aug(305):31-7. https://doi.org/10.1097/00003086-199408000-00005

11. Magu NK, Rohilla R, Arora S. Conservatively treated acetabular fractures: A retrospective analysis. Indian journal of orthopaedics. 2012 Jan;46(1):36. https:// doi.org/10.4103/0019-5413.91633; PMid:22345805 PMCid:PMC3270603 